\title{
Abordagens teóricas da Gestão Social: uma análise de citações exploratória
}

\author{
Theoretical approaches of Social Management: an exploratory citation analysis
}

\author{
Miguel Rivera Peres $\mathrm{Jr}^{1}$ \\ José Roberto Pereira²
}

\begin{abstract}
Resumo
O campo científico da Gestão Social conta com uma crescente produção acadêmica por meio da qual se discutem formas alternativas de gestão e que são caracterizadas por ações gerenciais dialógicas. Neste trabalho, objetiva-se identificar possíveis vertentes teóricas que emergem nesse campo. Para isso, é feita uma análise de citações dos trabalhos indexados na base Google Acadêmico, por meio da qual são delimitadas quatro abordagens teóricas que se explicam pelas fundamentações teóricas (abordagens crítica frankfurteana e da gestão do desenvolvimento social interorganizacional); pela origem de seus pesquisadores (abordagem puquiana) ou pelas singularidades (abordagem da administração pública societal, identificada com base nas especificidades de um modelo de gestão pública surgida no Brasil, que se contrapõe ao movimento gerencialista neoliberal dos anos 1980). Aponta-se, ainda, no trabalho, que entre as abordagens - pelo menos nos trabalhos de maior impacto -, temas comuns podem ser identificados, como a contraposição gestão social versus gestão estratégica; o terceiro setor como um espaço de ocorrência da gestão social; a proeminência de conceitos como participação, diálogo e busca do bem comum. A despeito dessas convergências, indica-se no trabalho que há uma subdivisão conceitual básica em duas vertentes: uma vinculando a gestão social estritamente à gestão pública, configurando-a como administração pública societal (PAES DE PAULA, 2005a; 2005b), gestão do desenvolvimento social (FISCHER, 2002) ou gestão do social (DOWBOR, 1999b), e outra que expande seu escopo a uma ação gerencial dialógica que pode (e deve) ser utilizada em sistemas sociais diversos - sejam eles públicos, privados ou organizações não governamentais (FRANÇA-FILHO, 2008; TENÓRIO, 2005).
\end{abstract}

Palavras-chave: Gestão Social. Bibliometria. Análise de Citações.

\section{Abstract}

The scientific field of Social Management has a growing academic research that discusses alternative forms of management, characterized by dialogical management actions. This study aims to identify possible theoretical issues that arise in this field. In order to do it, it is conducted a citation analysis of the papers indexed in Google Scholar, from which four theoretical approaches are defined, which are explained by the theoretical foundations (Frankfurt's critical

Artigo submetido em 13 de junho de 2013 e aceito em 31 de março de 2014.

DOI: http://dx.doi.org/10.1590/1679-39519079

1 Professor do Departamento de Gestão do Instituto Federal de Educação, Ciência e Tecnologia de Minas Gerais - IFMG - Campus Formiga. Doutor em Administração pela Universidade Federal de Lavras (UFLA). Endereço: Instituto Federal de Educação, Ciência e Tecnologia de Minas Gerais - IFMG - Campus Formiga. Rua Padre Alberico, 440 - São Luiz, CEP 35570-000, Formiga - MG, Brasil. E-mail: miguel.peres@ifmg.edu.br

2

Professor associado da Universidade Federal de Lavras (UFLA); Doutor em Sociologia pela Universidade de Brasília (UnB); Bolsista CNPq. Endereço: Universidade Federal de Lavras (UFLA). Programa de Pós-Graduação em Administração Pública (PPGAP). CX. Postal 3037, CEP 37200-000, Lavras - MG, Brasil. E-mail: jrobertopereira2013@gmail.com 
approach and the interorganizational social management development), the origin of its researchers ("puquiana" approach) or by singularities (societal approach of public administration, which is identified from the particular characteristics of a model of public management emerged in Brazil, opposed to the neoliberal management movement of the 1980s). Moreover, the paper shows that among the approaches - at least in the papers with greater impact - common themes can be identified, as the opposition social management versus strategic management; the third sector as an area of occurrence of social management; the prominence of concepts such as participation, dialogue and the common good. Despite these convergences, the paper indicates that there is a basic conceptual subdivision into two parts: one, linking social management strictly to public management, setting it as societal public administration (PAES DE PAULA, 2005a; 2005b), management of social development (FISCHER, 2002) or social management (DOWBOR, 1999b) and another that expands its scope towards a dialogic management action that can (and should) be used in various social systems whether public, private or non-governmental organizations (FRANÇA-FILHO, 2008; TENÓRIO, 2005).

Keywords: Social Management. Bibliometrics. Citation Analysis.

\section{Introdução}

Para vários autores (DOWBOR, 1999a; FISCHER, 2002; FISCHER e MELO, 2003; FRANÇA FILHO, 2008; PINHO, 2010; RIGO, SILVA JR., SCHOMMER et al., 2010), a Gestão Social, como campo de conhecimento científico, está em pleno processo de construção. Segundo Dowbor (1999a, p. 7), “[...] os paradigmas da gestão social ainda estão por ser definidos, ou construídos. É uma gigantesca área em termos econômicos, de primeira importância em termos políticos e sociais, mas com pontos de referência organizacionais ainda em elaboração.” Apesar disso, a área já conta, principalmente no Brasil, com estudos e debates dotados de atributos quantitativos e qualitativos que permitem indicar possíveis correntes teóricas e extrair alguns fundamentos conceituais que parecem indicar certo consenso.

É esse o objetivo principal deste trabalho: analisar essas possíveis vertentes teóricas que, apesar da "juventude" do campo da Gestão Social, começam a se destacar no cenário do conhecimento científico produzido no Brasil, buscando identificar os elementos em comum (fundamentações teóricas e temas discutidos) e as singularidades de cada uma. Para reconhecê-las, partiu-se de um levantamento bibliométrico, mais especificamente de uma análise de citações exploratória, que buscava identificar os autores e os trabalhos de maior impacto da área, supostamente representantes das vertentes mais influentes do campo no país.

\section{Conceitos Básicos dos Estudos Bibliométricos e Análise de Citações no Campo da Gestão Social}

A bibliometria é definida por Sengupta (1992) como uma técnica pela qual aspectos interconectados de comunicações escritas podem ser quantificados. Tague-Sutcliffe (1992) entende a bibliometria como o estudo dos aspectos quantitativos da produção, disseminação e uso da informação arquivada por meio de modelos matemáticos e métricas desses processos, que podem, posteriormente, ser utilizados para previsão e tomada de decisão.

De acordo com Vanti (2002), a aplicação das técnicas bibliométricas possibilita genericamente e entre outras funções: 1) identificar as tendências e o crescimento do conhecimento em uma área; 2) identificar as revistas do núcleo de uma disciplina; 3) prever as tendências de publicação; 4) estudar a dispersão e a obsolescência da literatura científica; 5) prever a produtividade de autores individuais, organizações e países; 6) medir o grau e padrões de colaboração entre autores; 7) analisar os processos de citação e cocitação; 8) avaliar os aspectos estatísticos da linguagem, das palavras e das frases; 9) medir o crescimento de determinadas áreas e o surgimento de novos temas. Recorre-se à bibliometria justamente no sentido apontado na primeira função 
destacada pela autora, ou seja, identificar de que forma vem se estruturando a produção científica da Gestão Social e se existem "correntes" teóricas sendo constituídas.

Uma das técnicas mais utilizadas pela bibliometria é a análise (ou estudo) de citações. Sengupta (1992) defende que o desenvolvimento dessa técnica - que se baseia na hipótese de que qualquer ato de citar o autor de um paper é significativo - representou um impulso significativo para a bibliometria. A análise de citações permite "[...] medir o impacto e a visibilidade de determinados autores dentro de uma comunidade científica, verificando quais 'escolas' do pensamento vigoram dentro das mesmas" (VANZ e CAREGNATO, 2003, p. 251). Para os autores, a análise de citações possibilita, também, a mensuração das fontes de informação utilizadas, como o tipo de documento, o idioma e os periódicos mais citados. Ainda de acordo com eles, a utilização destes indicadores permite determinar como se dá a comunicação científica de uma área do conhecimento, e possibilita, assim, seu "mapeamento", indicando teorias e metodologias consolidadas.

O surgimento e disponibilização para consulta pela internet de grandes bases de dados multidisciplinares Web of Science (WoS), SciVerse Scopus (SVS), Scientific Electronic Library Online (SciELO) e o Google Acadêmico, entre outras - facilitaram enormemente os estudos bibliométricos. Mugnani e Strehl (2008) defendem que o fato de a indexação dos artigos - outro ponto nevrálgico do processo - estar sendo feita pelos chamados motores de busca da internet, como o Google Acadêmico, democratizam as pesquisas e, em muitos casos, o acesso a conteúdos disponibilizados pela web.

Mugnani e Strehl (2008, p. 93) apontam, ainda, outro benefício do advento dos mecanismos de recuperação de informações bibliométricas disponibilizados pela internet, em particular os gratuitos. Para os autores, artigos que antes poderiam ter dificuldades em superar os "quesitos impostos pela sofisticada indústria editorial dos países desenvolvidos" passariam a "ter maior chance de serem reconhecidos por suas qualidades intrínsecas". Nesse sentido, eles argumentam que temáticas relevantes para o "Terceiro Mundo", mas que não seduzem os periódicos do "Primeiro Mundo", passariam a gozar de um espaço de divulgação facilitado e acesso irrestrito.

Por se entender que é esse o caso da Gestão Social - um tema ainda novo e no qual textos latino-americanos, em especial brasileiros, são majoritários e, portanto, sem grande penetração nos periódicos do mainstream acadêmico -, optou-se, neste trabalho, pela utilização do Google Acadêmico como ferramenta de suporte na identificação das principais correntes teóricas de discussão do tema no Brasil. Para isso, foram considerados os trabalhos retornados na busca ${ }^{3}$ do termo "gestão social" com pelo menos 10 citações naquela base de dados (Tabela 1).

Tabela 1

Trabalhos de maior impacto no campo da Gestão Social - Google Acadêmico - março de 2012

\begin{tabular}{|c|l|c|}
\hline Ranking & \multicolumn{1}{|c|}{ Referência } & Citações \\
\hline 01 & $\begin{array}{l}\text { CECCIM, R.; FEUERWERKER, L. O quadrilátero da formação para a área da } \\
\text { saúde: ensino, gestão, atenção e controle social. Physis, v. 14, n. 1, p. 41- } \\
65,2004 .\end{array}$ & 198 \\
\hline 02 & $\begin{array}{l}\text { TENÓRIO, F. G. Gestão social: uma perspectiva conceitual. Rev. Adm. } \\
\text { Pública, v. 32, n. 5, p. 7-23, 1998. }\end{array}$ & 92 \\
\hline
\end{tabular}

\footnotetext{
${ }^{3}$ Pesquisa realizada em 24 de março de 2012 com utilização do termo gestão social entre aspas, o que limita a busca à frase exata.
} 


\begin{tabular}{|c|c|c|}
\hline 03 & $\begin{array}{l}\text { PAES DE PAULA, A. P. Administração pública brasileira entre o } \\
\text { gerencialismo e a gestão social. RAE, v. } 45, \text { n. } 1, \text { p. } 36-49,2005 .\end{array}$ & 51 \\
\hline 04 & $\begin{array}{l}\text { DOWBOR, L. A gestão social em busca de paradigmas. In: RICO, E. D. M.; } \\
\text { RAICHELIS, R. (Orgs.). Gestão social: uma questão em debate. São Paulo: } \\
\text { EDUC/IEE, 1999. p. 31-42. }\end{array}$ & 51 \\
\hline 05 & $\begin{array}{l}\text { TENÓRIO, F. G. (Org.). Gestão social: metodologia, casos e práticas. Rio de } \\
\text { Janeiro: FGV, } 1998 .\end{array}$ & 45 \\
\hline 06 & $\begin{array}{l}\text { DOWBOR, L. Gestão social e transformação da sociedade. In: } \\
\text { KILSZTAIN, S. (Orgs.). Economia social no Brasil. São Paulo: Senac, 2001. p. } \\
\text { 17-42. }\end{array}$ & 40 \\
\hline 07 & $\begin{array}{l}\text { CARVALHO, M. C. B. Gestão social: alguns apontamentos para debate. In: } \\
\text { RICO, E. M.; RAICHELIS, R. (Orgs.). Gestão social: uma questão em debate. } \\
\text { São Paulo: EDUC/IEE, 1999. p. 19-29. }\end{array}$ & 39 \\
\hline 08 & $\begin{array}{l}\text { SILVA, A. A. A gestão da seguridade social brasileira: entre a política } \\
\text { pública e o mercado. São Paulo: Cortez, } 2004 \text {. }\end{array}$ & 32 \\
\hline 09 & $\begin{array}{l}\text { RICO, E. M.; RAICHELIS, R. (Orgs.). Gestão social: uma questão em debate. } \\
\text { São Paulo: EDUC/IEE, } 1999 .\end{array}$ & 27 \\
\hline 10 & $\begin{array}{l}\text { TENÓRIO, F. G. (Re)visitando o conceito de gestão social. Desenvolvimento } \\
\text { em Questão, v. 3, n. 5, p. 101-124, } 2005 .\end{array}$ & 25 \\
\hline 11 & $\begin{array}{l}\text { ROSSONI, L.; SILVA, A.; FERREIRA JÚNIOR, I. Aspectos estruturais da } \\
\text { cooperação entre pesquisadores no campo de administração pública e } \\
\text { gestão social: análise das redes entre instituições no Brasil. Rev. Adm. } \\
\text { Pública, v. } 42 \text {, n. } 6 \text {, p. 1041-1067, } 2008 \text {. }\end{array}$ & 19 \\
\hline 12 & $\begin{array}{l}\text { CAVALCANTI, M.; NOGUEIRA, A. Gestão social, estratégias e parcerias: } \\
\text { redescobrindo a essência da administração brasileira de comunidades para } \\
\text { o Terceiro Setor. São Paulo: Saraiva, } 2006 \text {. }\end{array}$ & 19 \\
\hline 13 & $\begin{array}{l}\text { FRANÇA FILHO, G. C. Definindo gestão social. In: SILVA JUNIOR, J. T. et al. } \\
\text { (Orgs.). Gestão Social: práticas em debate, teorias em construção. } \\
\text { Fortaleza: Imprensa Universitária, 2008. p. 26-37. }\end{array}$ & 19 \\
\hline 14 & $\begin{array}{l}\text { DOWBOR, L. Tendências da gestão social. Saúde e Sociedade, v. 8, n. 11, p. } \\
3-16,1999 .\end{array}$ & 18 \\
\hline 15 & $\begin{array}{l}\text { TENÓRIO, F. G.; SARAVIA, E. J. Escorços sobre gestão pública e gestão } \\
\text { social. In: MARTINS, P. E. M.; PIERANTI, O. P. Estado e gestão pública: } \\
\text { visões do Brasil contemporâneo. Rio de Janeiro: FGV, } 2006 \text {. }\end{array}$ & 17 \\
\hline
\end{tabular}




\begin{tabular}{|c|c|c|}
\hline 16 & $\begin{array}{l}\text { FARAH, M. F. S. Governo local e novas formas de provisão e gestão de } \\
\text { serviços públicos no Brasil. Rev. Adm. Pública, v. 31, n. 3, p. 191-192, } 1997 .\end{array}$ & 17 \\
\hline 17 & $\begin{array}{l}\text { FRANÇA FILHO, G. C. Gestão social: um conceito em construção. In: } \\
\text { COLÓQUIO INTERNACIONAL SOBRE PODER LOCAL, 9., Salvador, Bahia. } \\
\text { Anais..., Salvador: UFBA, } 2003 .\end{array}$ & 12 \\
\hline 18 & $\begin{array}{l}\text { TENÓRIO, F. G. Um espectro ronda o terceiro setor: o espectro do } \\
\text { mercado. Ensaios de Gestão Social. Ijuí: Unijuí, } 2004 \text {. }\end{array}$ & 12 \\
\hline 19 & $\begin{array}{l}\text { HOCAYEN-DA-SILVA, A. J.; ROSSONI, L.; FERREIRA-JÚNIOR, I. Administração } \\
\text { pública e gestão social: a produção científica brasileira entre } 2000 \text { e } 2005 . \\
\text { Rev. Adm. Pública, v. 42, n. 4, p. } 655-680,2008 \text {. }\end{array}$ & 11 \\
\hline 20 & $\begin{array}{l}\text { TENÓRIO, F. G. A trajetória do Programa de Estudos em Gestão Social } \\
\text { (PEGS). Rev. Adm. Pública, v. 40, n. 6, p. 1145-1162, } 2006 .\end{array}$ & 11 \\
\hline 21 & $\begin{array}{l}\text { TENÓRIO, F. G.; DUTRA, J. L. A.; MAGALHÃES, C. M. R. Gestão social e } \\
\text { desenvolvimento local: uma perspectiva a partir da cidadania deliberativa. } \\
\text { In: EnANPAD, 28., 2004, Curitiba. Anais... Rio de Janeiro: ANPAD, } 2004 .\end{array}$ & 11 \\
\hline 22 & $\begin{array}{l}\text { FISCHER, T.; MELO, V. P. Gestão Social do desenvolvimento e } \\
\text { interorganizações. In: COLÓQUIO INTERNACIONAL SOBRE PODER LOCAL, } \\
\text { 12., Anais... Salvador: UFBA, } 2003 .\end{array}$ & 10 \\
\hline
\end{tabular}

Fonte: elaborado pelos autores.

Algumas observações devem ser feitas em relação aos trabalhos elencados na Tabela 1. A primeira delas refere-se aos trabalhos 01, 08, 11 e 19, que foram excluídos da análise para identificação de possíveis correntes teóricas da Gestão Social. Os de número 01 (CECCIM e FEUERWERKER, 2004) e 08 (SILVA, 2004) não foram considerados na análise por não utilizarem o termo "gestão social" de forma conceitual. Não há, nas discussões desses autores, um delineamento teórico sobre o que seria a gestão social, mas, sim, discussões sobre áreas específicas (saúde e seguridade social respectivamente), que, apesar de relevantes, não contribuem para a construção da Gestão Social enquanto campo de conhecimento científico. Da mesma forma, não influenciaram nessa avaliação, os trabalhos 11, de Rossoni, Silva e Ferreira Júnior (2008), que avaliam estrutura de relacionamento entre instituições de pesquisa no campo de Administração Pública e Gestão Social no Brasil, por meio de uma análise de rede, e o 19, de Hocayen-da-Silva, Rossoni e Ferreira Júnior (2008), em que é apresentado um quadro geral da produção científica (estudo bibliométrico) em Administração Pública e Gestão Social com base nos dados levantados em artigos publicados nos anais do EnANPAD entre os anos de 2000 e 2005. Entende-se a Figura para a consolidação do campo da Gestão Social, indicando padrões de comportamento da produção científica da área, não se aplicam ao tipo de avaliação que aqui se pretende, qual seja, a de identificar possíveis vertentes teóricas.

Cabe destacar que a bibliometria e suas técnicas permitiriam a produção de vários indicadores de atividade científica (número de trabalhos publicados por autor, grupo de pesquisa, universidade, etc.); indicadores relacionais (copublicações - entre autores, instituições, etc. -; índice de afinidade, conexões científicas medidas por citações, correlações entre trabalhos, cocitações, coocorrência de palavras (frequência de pares 
de palavras que aparecem em um conjunto de textos) (OKUBO, 1997); e indicadores de performance, desenvolvidos com o objetivo de medir o desempenho tanto de periódicos científicos (determinado, principalmente, por seu Fator de Impacto $^{4}$ ) quanto de pesquisadores (que têm no h-index ${ }^{5}$ um dos indicadores de maior relevância) (DURIEUX e GEVENOIS, 2010). Não sendo, no entanto, objetivo deste trabalho aprofundar-se nas análises bibliométricas, restringir-se-á a análise ao número de citações relativo aos trabalhos da área de Gestão Social no Google Acadêmico. Acredita-se que, para os fins deste estudo, essa estratégia seja suficiente.

\section{Convergências e Singularidades das Abordagens Teóricas da Gestão Social}

Conforme se viu na seção precedente, objetivando reconhecer as possíveis vertentes do campo da Gestão Social, fez-se um levantamento bibliométrico que buscou identificar os trabalhos de maior impacto do campo (entendendo, como prevê as técnicas de bibliometria, que o número de citações recebidas é uma métrica importante de impacto). Elencados os textos mais influentes, procurou-se agrupá-los por meio de algum elemento comum (referenciais utilizados; proposições teóricas; instituições de atuação, etc.) que possibilitasse criar grupos com alguma homogeneidade. Esse esforço redundou na identificação de quatro grupos de trabalhos (e autores) que, aparentemente, podem ser apontados como as principais "escolas de pensamento" do campo da Gestão Social. São elas:

1. corrente derivada da teoria crítica frankfurtena, na qual se destacam os trabalhos de Fernando Guilherme Tenório, da EBAPE/FGV e de Genauto Carvalho de França Filho, da Universidade Federal da Bahia (UFBA);

2. aquela baseada na noção de gestão do desenvolvimento social conduzido por interorganizações, desenvolvida pela Prof. ${ }^{a}$ Tânia Maria Diederichs Fischer, coordenadora do Centro Interdisciplinar de Desenvolvimento e Gestão Social (CIAGS), da Universidade Federal da Bahia (UFBA);

3. abordagem centrada nos conceitos de administração pública societal, de Ana Paula Paes de Paula (UFMG);

4. abordagem puquiana, que recebe esse nome tendo em vista a origem e/ou local de atuação de seus autores - a Pontifícia Universidade Católica de São Paulo (PUC/SP) -, na qual se destacam os textos de Ladislau Dowbor e os livros Gestão social: uma questão em debate (RICO e RAICHELLIS, 1999) e Gestão social, estratégias e parcerias: redescobrindo a essência da administração brasileira de comunidades para o Terceiro Setor (CAVALCANTI e NOGUEIRA, 2006).

Duas análises - entre as várias possíveis - foram feitas por meio da delimitação dessas abordagens. A primeira buscou mapear as referências teóricas utilizadas, identificando quais correntes do pensamento podem ter influenciado cada abordagem. Concepções comuns (ou pelo menos similares) entre as abordagens é outra apreciação feita com base na delimitação das vertentes da Gestão Social no Brasil.

No que se refere ao mapeamento dos embasamentos teóricos que fundamentam as abordagens da Gestão Social identificadas, percebe-se que, apesar de algumas concepções distintas, elas apresentam várias

\footnotetext{
${ }^{4}$ O Fator de Impacto é definido pela razão entre o número de citações no corrente ano a itens publicados em um periódico nos últimos dois anos e o número de artigos (itens fonte) publicados nos mesmos dois anos pelo mesmo periódico (STREHL, 2005, p. 20).

${ }^{5}$ Desenvolvido por Jorge Hirsch, o Hirsch index (ou, como é mais conhecido, h-index) indica o impacto das publicações de um pesquisador. Um cientista com h-index=40, por exemplo, possui 40 trabalhos publicados que receberam, no mínimo, 40 citações (BORNMANN e DANIEL, 2007).
} 
conexões e pontos de partida comuns em suas formulações. A Figura 1, que ilustra essas relações, mostra, por exemplo, a influência que as ideias de Boaventura Sousa Santos, Bernardo Kliksberg e Alberto Guerreiro Ramos têm sobre as abordagens da Gestão Social. Pode-se dizer que provém desses três autores boa parte dos conceitos que fundamentam vertentes identificadas.

Entre eles, a influência do primeiro parece ser a maior. Em todas as abordagens, o sociólogo português é citado, em especial seu livro Democratizar a democracia: os caminhos da democracia participativa, publicado originalmente no Brasil em 2002. Para Wanderley e Raichellis (2001) - da abordagem puquiana esse autor faz uma estimulante análise do relacionamento entre três pilares da regulação social na modernidade ocidental: sociedade, Estado e mercado. Pereira e Rigatto (2011, p. 25), situados na vertente crítica frankfurteana, destacam que, na visão do autor português, deve-se cada vez mais, "[...] democratizar a sociedade e, em um movimento dialético, democratizar o próprio Estado". Paes de Paula (2005a) concorda e aponta um novo paradigma reformista da administração pública proposto por Santos (2006, p. 49), no sentido de converter o Estado em componente do espaço público não estatal, o que denomina de "Estado como novísimo movimiento social".

Já Bernardo Kliksberg é tido como o pioneiro das discussões sobre Gestão Social - no caso específico, gerência social - na América Latina (TENÓRIO, 2009). Os puquianos Alves Sobrinho e Inojosa (2005) destacam a respeito desse autor - segundo eles, um estudioso dedicado à gestão social e à desigualdade - sua proposta que realça a necessidade de se repensar a Gestão Social em quatro dimensões: acesso das áreas sociais aos centros de poder; coordenação interna da área social; articulação de redes e participação.

Sobre Alberto Guerreiro Ramos, Fischer (2002) ressalta seu papel precursor nas discussões sobre a possibilidade e necessidade de uma nova administração, incluindo a esfera pública. Ela aponta, ainda, a relevância do sociólogo baiano no ensino da Administração Pública, destacando seu diagnóstico de que a prática da Administração Pública e o ensino estariam desconectados, havendo um hiato entre o que se sabe e o que se precisa saber (FISCHER, 1984). As reflexões de Guerreiro Ramos sobre racionalidade substantiva em oposição à racionalidade instrumental (ou técnica; ou funcional) também estão presentes em alguns textos analisados, em especial na abordagem crítica frankfurteana (FRANÇA FILHO, 2008; TENÓRIO, 2002; 2006) e constituem elemento central dos pressupostos dessa abordagem.

Figura 1

\section{Relações teóricas entre as abordagens da Gestão Social}

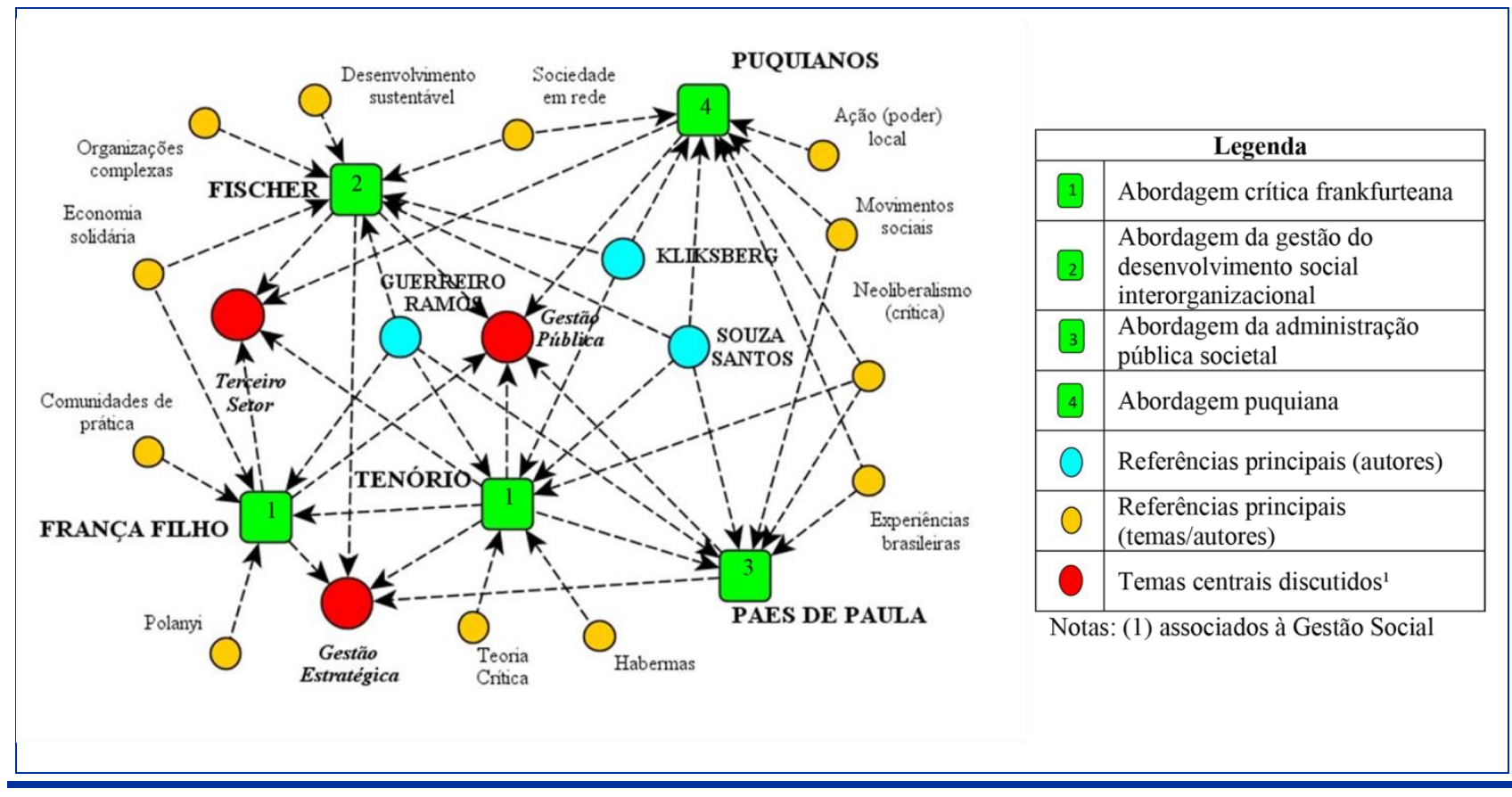


Fonte: elaborado pelos autores.

A análise dos movimentos sociais brasileiros é outro tema, como se observa na Figura 1, frequentemente utilizado pelas abordagens da Gestão Social. Além de Paes de Paula (2005a; 2005b), os puquianos (ALVES SOBRINHO e INOJOSA, 2005; CARVALHO, 1999; WANDERLEY, 1999) valem-se de relatos sobre iniciativas concretas de participação popular por meio dos movimentos sociais em suas discussões sobre Gestão Social. Estreitamente interligada ao tema dos movimentos sociais, a discussão sobre o Terceiro Setor também ocupa papel relevante nas abordagens sobre Gestão Social (CABRAL, 2003; 2006; 2008; 2011; DOWBOR, 1999a; 1999b; JUNQUEIRA, 2004; TENÓRIO, 2004 e outros).

Outra convergência entre as abordagens puquiana e da administração pública societal ocorre no apoio em experiências concretas de participação popular. Na vertente da administração pública societal o tema é discutido também com base na visão de Tarso Genro que, como prefeito e vice-prefeito de Porto Alegre, relata as experiências de orçamento participativo desenvolvidas na capital gaúcha em vários textos publicados ao longo da década de 1990 (PAES DE PAULA, 2005a; 2005b). Na análise das experiências brasileiras de participação popular, explicita-se, na abordagem puquiana, uma aproximação com o trabalho desenvolvido pelos pesquisadores da EAESP/FGV. Em vários textos essa conexão é demonstrada, como, por exemplo, no capítulo "A democratização do poder local: gestão social na ótica subnacional" (SPINK, 1999), publicado no livro Gestão social: uma questão em debate (RICO e RAICHELIS, 1999). Peter Spink é um dos pesquisadores da EAESP/FGV que pode ser vinculado à abordagem puquiana e que investiga casos específicos de participação popular nas decisões públicas.

Observa-se, dessa forma, que há inúmeros temas comuns às abordagens identificadas. Nota-se, contudo, que há especificidades que distinguem cada uma das vertentes. O embasamento na Escola de Frankfurt e nos pressupostos habermasianos na abordagem crítica, por exemplo, pode ser assumido como a maior característica dessa vertente. Já Genauto França Filho (2003; 2008), que no presente trabalho também vincula-se a ela, apresenta algumas particularidades em relação às suas fundamentações teóricas para discussão da Gestão Social: 1) aproximação teórica com a economia solidária; 2) referências ao substantivismo de Karl Polanyi; 3) introdução das concepções de comunidades de prática, principalmente como espaços de aprendizagem da gestão social. A principal distinção da abordagem da gestão do desenvolvimento social interorganizacional é, como o próprio nome sugere, a ênfase no conceito de interorganizações (ou organizações complexas) - para a autora, indispensável à coletivização da gestão, “[...] não apenas nas corporações, mas em todas as instâncias da sociedade" (FISCHER, 2002, p. 26). Diferentemente, na abordagem da administração pública societal, a ênfase recairia na análise de modelos e práticas de gestão pública - em especial aquelas adotadas no Brasil - para, por meio dessa avaliação, estabelecer modelos alternativos e mutuamente excludentes (pelo menos na visão de Paes de Paula, 2005c): gerencialismo e administração pública societal. Vê-se, finalmente, que na abordagem puquiana privilegia-se a discussão de iniciativas de exercício do poder local por meio da investigação de casos concretos, do Brasil e do exterior - neste último, basicamente por meio de Dowbor (1999a; 1999b; 2001 e outros).

Outra análise empreendida procurou extrair alguns fundamentos conceituais que parecem indicar certo consenso. Alguns trabalhos já trazem revisões do campo que indicam princípios (PIMENTEL e PIMENTEL, 2010), características básicas (OLIVEIRA, CANÇADO e PEREIRA, 2010) e categorias teóricas da Gestão Social (CANÇADO, 2011).

Oliveira, Cançado e Pereira (2010) identificaram algumas características básicas da Gestão Social: 1) a tomada de decisão coletiva, livre de coerção e baseada no entendimento; 2) a adoção da transparência como um valor e da linguagem inteligível como uma norma; e 3) a emancipação dos seres humanos como o valor maior a ser alcançado. Pimentel e Pimentel (2010), além da deliberação coletiva, apontam outros seis princípios que caracterizam o campo da Gestão Social: 1) interesse coletivo de caráter público como objetivo; 2) interesse público como orientação de valor; 3) subordinação da lógica instrumental a um processo decisório deliberativo, ao mesmo tempo em que se busca atender às necessidades de dado sistema social; 4) sociedade civil organizada como protagonista, mas sem deixar de envolver todos os atores sociais, 
organizacionais e institucionais de um dado espaço; 5) processo participativo, dialógico, consensual; e 6) parcerias e redes intersetoriais, tanto práticas como de conhecimentos, como forma de pensar e de operacionalização.

Cançado (2011), em sua tese de doutorado em Administração, ao pesquisar em periódicos, livros, teses e dissertações, identificou diversas categorias teóricas que tratam da gestão social como conceito e como sinônimo de outro tipo de gestão, são elas: Gestão Social, Gestão Emancipatória, Gestão Participativa, Gestão do Desenvolvimento Social e Gestão de Organizações sem Fins Lucrativos. Estas categorias evidenciam o caráter interdisciplinar dos trabalhos produzidos nessa área e a grande variação no entendimento sobre gestão social, bem como as distintas abordagens teóricas em que se fundamentam. Em alguns textos trata-se, especificamente, do conceito de gestão social, em diferentes abordagens teóricas. Em outros textos interpreta-se a gestão social como uma gestão que proporciona a emancipação ou empoderamento das pessoas. A gestão social é tratada, também, como gestão participativa pelo fato de nela a participação ou a cidadania deliberativa ser considerada como elemento central na análise dos textos. No entanto, há textos em que se entende a gestão social como gestão de projetos ou programas sociais, políticas públicas e como aspectos sociais da administração pública. Há, ainda, aqueles que entendem a gestão social como gestão de ONGs, do terceiro setor, de cooperativas ou gestão de qualquer organização sem fins lucrativos. E, também, textos em que se interpreta a gestão social como responsabilidade socioambiental, gestão socioambiental e gestão ambiental. Após analisar todas essas categorias nos mais diversos textos encontrados na literatura científica brasileira, Cançado (2011) considera que o campo de conhecimento da Gestão Social fundamenta-se, teoricamente, em três grandes categorias articuladas entre si e que abrangem as demais categorias, em uma sequência ascendente, qual seja: interesse público; esfera pública; e emancipação social. Essas grandes categorias teóricas foram tratadas e desenvolvidas pelo referido autor em sua tese, que ao final apresenta o seguinte conceito de gestão social: "[...] é a tomada de decisão coletiva, sem coerção, baseada na inteligibilidade da linguagem, na dialogicidade e entendimento esclarecido como processo, na transparência como pressuposto e na emancipação enquanto fim último" (CANÇADO, 2011, p. 221).

Partindo das sistematizações feitas por esses autores e da delimitação das abordagens feitas neste trabalho, entende-se que algumas concepções básicas, que parecem constituir certo consenso, podem ser percebidas na produção científica da Gestão Social e merecem ser analisadas de maneira mais aprofundada. A primeira delas refere-se à caracterização da gestão social como a ação gerencial que tem, como preocupações básicas, o bem comum (FRANÇA FILHO, 2008; FISCHER, 2007; TENÓRIO, 1998b; 2005) e o atendimento de necessidades sociais (FRANÇA FILHO, 2008; INOJOSA e JUNQUEIRA, 2006). Dessa perspectiva, a gestão social seria aquela que tem como motivação e objetivos básicos não o atendimento de interesses estratégicos, quer sejam individuais ou organizacionais, mas, sim, o alcance do bem comum traduzido no desenvolvimento social, o que a aproximaria da noção de gestão pública.

Desde Kliksberg (1997), a gerência social - como ele denomina a ação gerencial voltada ao social - está relacionada com a otimização dos esforços do Estado e dos atores sociais no enfrentamento dos déficits sociais por meio da gestão eficiente das políticas sociais. Em todas as abordagens o conceito de gestão social também está estreitamente vinculado ao de gestão pública. No enfoque da administração pública societal, a gestão social é, inclusive, uma abordagem específica da gestão pública que enfatiza "[...] a elaboração de experiências de gestão focalizadas nas demandas do público-alvo, incluindo questões culturais e participativas" (PAES DE PAULA, 2005a, p. 41). Também na vertente puquiana a gestão social é definida como "gestão das ações públicas", mais especificamente a "gestão das demandas e necessidades dos cidadãos" (CARVALHO, 1999, p. 19).

Da perspectiva da gestão do desenvolvimento social interorganizacional, o conceito é expandido. Para Fischer (2007, p. 1), um dos grandes problemas contemporâneos está na "[...] ausência da dimensão social da gestão, tanto na ação isolada e descontextualizada de gestores governamentais e não-governamentais como na perspectiva dos cidadãos que se utilizam de serviços públicos". A autora entende que o desenvolvimento deve estar baseado na ideia de sustentabilidade, em uma visão integrada dos aspectos sociais, econômicos, 
políticos, culturais e ambientais inerentes a qualquer local, e na articulação dos atores sociais das diversas esferas (Estado, sociedade e mercado) (FISCHER, 2007).

$\mathrm{Na}$ abordagem crítica frankfurteana, essa associação também é feita. Tenório (2005, p. 107) relaciona a gestão social com a gestão pública, mas, para ele, trata-se de uma "administração pública ampliada". Segundo esse autor, configura-se uma gestão social quando é necessário tomar uma decisão que afeta uma determinada comunidade ou território e todos os envolvidos participam como protagonistas - primeiro setor (Estado); segundo setor (mercado) e terceiro setor (sociedade civil) - (TENÓRIO, 2005, p. 107). Ao sugerir que gestão social pode ser vista como uma problemática da sociedade, França Filho (2008) também aproxima o conceito da noção de gestão pública. Ele ressalta, no entanto, que "[...] para além do Estado, a gestão das demandas e necessidades do social pode se dar via a própria sociedade, através das suas mais diversas formas e mecanismos de auto-organização, especialmente o fenômeno associativo" (2008, p. 2930).

França Filho (2008), apesar de ser enquadrado na abordagem crítica originada em Tenório, segue caminho um pouco distinto e propõe uma interpretação do conceito de gestão social no qual busca considerar duas dimensões: a de processo ou meio (como opera a gestão) e aquela de finalidade (os objetivos da gestão). Para isso, ele incorpora dois níveis de análise de percepção da gestão social: a problemática da sociedade (nível societário; macro) e aquele associado a uma modalidade específica de gestão (nível organizacional; micro ou meso). Enquanto problemática da sociedade, o conceito de gestão social está vinculado à gestão das demandas e necessidades do social. Como tradicionalmente a gestão das demandas da sociedade coube aos poderes públicos, tende-se a confundir a gestão social com a gestão pública. Apesar de o Estado ainda ser responsável por grande parte das ações voltadas ao atendimento das demandas e necessidades sociais, o que o autor defende é que a sociedade também pode atuar nesse campo por meio das diversas formas de autoorganização existentes, em especial o associativismo (FRANÇA FILHO, 2008).

Já a gestão social, como processo ou meio, pode ser pensada como um modo de orientação para uma ação organizacional que inverte a relação entre as racionalidades ao colocar a lógica instrumental - que prevalece nas outras formas de gestão - subordinada às demais (social, cultural, política, ecológica) (FRANÇA FILHO, 2008). Percebe-se que, dessa perspectiva, a gestão social pode (e deve) ocorrer tanto no âmbito público, por meio de uma administração pública participativa, quanto nas esferas privada e não governamental, por meio de uma flexibilização organizacional que permita que, no processo de tomada de decisão do sistema-empresa, o envolvimento e a participação dos trabalhadores sejam aceitos e incentivados, possibilitando uma ação gerencial participativa (TENÓRIO, 2002).

Nesse contexto, pode-se inferir que a flexibilização organizacional e a ação gerencial participativa só se darão por meio de um processo de democratização do espaço organizacional. Para que isso ocorra, é imperativo que os atores apresentem suas propostas sobre bases racionais e que o acordo seja alcançado comunicativamente, por meio do diálogo e do entendimento, e não por outras pretensões de validade - como a posição hierárquica e a racionalidade instrumental (TENÓRIO, 2002).

Emerge, assim, outro aspecto proeminente nas discussões sobre Gestão Social: o diálogo. Schommer e França Filho $(2008$, p. 62) apontam a centralidade do diálogo nas discussões sobre o tema, destacando que têm trabalhado com uma concepção de gestão social que "valoriza os processos coletivos, dialogados e participativos da gestão". Também para Tenório (2005), o diálogo é característica central, o que o leva a estabelecer que a gestão social pode ser entendida como o processo gerencial dialógico em que a autoridade decisória é compartilhada entre os participantes da ação. Gondim, Fischer e Melo (2006, p. 12) alertam, contudo, que:

Para fazer jus a uma gestão social que privilegie o social e a participação cidadã, que seja hábil em conciliar as diversas dimensões econômicas e não-econômicas, que balize a instrumentalidade e a substantividade, assim como o consenso e a diversidade, e ainda que 
torne prevalente o diálogo e a interlocução de todos os atores sociais, há um longo caminho a percorrer, dada a complexidade desta missão.

Explicita-se, aqui, outro conceito caro às discussões da Gestão Social: o de participação. Vários dos pesquisadores da área apontam a participação como elemento central da gestão social (FISCHER, 2002; 2007; OLIVEIRA, CANÇADO e PEREIRA, 2010; PAES DE PAULA, 2005a; 2005b; TENÓRIO, 1998b; 2005). Nesse tema, a referência principal é o já mencionado Boaventura Sousa Santos, mas, principalmente na abordagem crítica frankfurteana, recorre-se muito a Pedro Demo (TENÓRIO, 1998b; 2005; 2006) nas discussões sobre participação popular nas decisões públicas. Pedro Jacobi, Professor Titular da Faculdade de Educação e do Programa de Pós-Graduação em Ciência Ambiental (PROCAM/USP) da Universidade de São Paulo, é outra referência importante sobre o tema (PAES DE PAULA, 2005a; 2005b; TENÓRIO, 1998b; 2005; 2006).

Tenório (2005) é um dos que privilegiam sobremaneira a dimensão participativa na gestão social. Segundo ele, a ênfase da participação nas discussões sobre gestão social busca destacar o caráter essencialmente intersubjetivo e dialógico do conceito. A participação integra também as propostas de Tenório (2005, p. 113) como forma de ampliar o pensamento habermasiano - que fundamenta boa parte de suas propostas atribuindo-lhe a característica de ser "[...] o procedimento da prática da cidadania deliberativa na esfera pública".

Participação constitui, assim, elemento fundamental nas discussões de orientação crítica sobre gestão social. De acordo com Demo (1989, p. 77), "[...] participar significa ter consciência da condição social imposta de discriminação e, a partir daí, construir caminho próprio de superação possível". O autor acrescenta que o fenômeno participativo é complexo e não se esgota apenas na esfera política.

A complexidade do mundo contemporâneo, com a rediscussão de deveres e responsabilidades entre o Estado, a sociedade civil e o mercado no atendimento das necessidades sociais, representa um desafio e um estímulo para a participação no processo democrático. Conforme destaca R. M. Fischer ${ }^{6}$ (2005, p. 9):

Evidenciadas as mazelas da exclusão social e do desequilíbrio da distribuição de renda, ressaltadas as distâncias entre os países de economia desenvolvida e as inúmeras periferias miseráveis, a constatação é de que a responsabilidade pelo desenvolvimento humano está distribuída entre todos os atores sociais, estejam eles inseridos em organizações públicas, empresariais ou de participação da sociedade civil.

A participação torna-se, assim, um importante vetor para o desenvolvimento local com cidadania. Conforme afirma Tenório (2005, p. 119), isso significaria que as pessoas, individualmente ou atuando em "[...] grupos organizados da sociedade civil, bem como do empresariado local (do mercado) em interação com o poder público municipal (Executivo e Legislativo), decidem sob uma esfera pública, quanto ao bem-estar da comunidade".

Vislumbra-se outra concepção que amiúde aparece nos textos de Gestão Social: a de terceiro setor. Defendese que é nos espaços públicos que o terceiro setor encontra sua arena de atuação; espaço este situado na interseção entre o Estado, o mercado e a sociedade. Segundo Cabral (2011, p. 51):

Tratando o bem público como produto social do encontro entre o Estado, o mercado e a comunidade, necessária e indistintamente usufruídos pelos cidadãos, pode-se dizer que esses bens, em sua qualidade e forma, respondem ao confronto entre a representação da vontade dos cidadãos, o exercício do poder do Estado e a capacidade produtiva do mercado.

${ }^{6}$ Todas as demais citações a "Fischer" referem-se à Tânia Maria Diederichs Fischer. 
Para a autora, que pode ser enquadrada na abordagem puquiana, o terceiro setor, quando visto como a manifestação desse espaço público, pode ser identificado por sua estrutura de atributos normativos que se traduzem em novas sociabilidades voltadas para a produção de bens públicos e reprodução dos valores sociais estimados (CABRAL, 2011). De acordo com Wanderley (2006), este espaço público (que ele chama de não estatal) onde se realizam essas sociabilidades apresenta determinados atributos identificados nos valores: representação de interesses coletivos; democratização; qualidade; efetividade; visibilidade; cultura pública; autonomia; controle e defesa social; e sustentabilidade.

Para Junqueira (2006), a configuração desse espaço de atuação das organizações do terceiros setor no Brasil foi favorecida pelo cenário de modernização do Estado, no qual o conceito de descentralização ganha força. Nesse contexto, as ONGs:

[...] ganham espaço na cena política, passando a constituir uma alternativa de eficácia à gestão das políticas sociais. O Estado, sem se eximir de sua responsabilidade, transfere algumas de suas competências para organizações da sociedade civil, as quais passam a assumir, em caráter complementar em parceria, as ações sociais que possibilitam oferecer à população melhores condições de vida. (JUNQUEIRA, 2006, p. 199).

Percebe-se que, apesar de recente, o campo da Gestão Social já possui alguns elementos conceituais de ampla utilização. Concepções como participação, diálogo, terceiro setor e bem comum (entre outros) parecem ser aceitos como pertinentes ao estudo do tema de forma praticamente consensual por boa parte dos teóricos do campo. Acredita-se que a definição apresentada por Cançado, Tenório e Pereira (2011, p. 697) sintetiza e traduz essas concepções consensuais:

Em síntese, a gestão social pode ser apresentada como a tomada de decisão coletiva, sem coerção, baseada na inteligibilidade da linguagem, na dialogicidade e no entendimento esclarecido como processo, na transparência como pressuposto e na emancipação enquanto fim último.

\section{Considerações Finais}

Este artigo teve como objetivos centrais analisar as possíveis vertentes teóricas que poderiam estar emergindo no campo da Gestão Social no Brasil, buscando identificar nessas "escolas" os elementos em comum (fundamentações teóricas e temas discutidos) e as singularidades de cada uma. Para alcançá-los, fezse uma análise de citações exploratória, que elencou os autores e os trabalhos de maior impacto da área, valendo-se da base de dados do Google Acadêmico.

Acredita-se que esses objetivos foram alcançados. A delimitação das quatro abordagens sugeridas parece se justificar na medida em que elas se explicam não só pelo impacto (número de citações) de seus principais trabalhos, mas, também, por suas fundamentações teóricas (as abordagens crítica frankfurteana e da gestão do desenvolvimento social interorganizacional); pela origem de seus pesquisadores (a abordagem puquiana) ou por suas singularidades (a administração pública societal, que é proposta por meio das especificidades de um modelo de gestão pública surgida no Brasil que se contrapõe ao movimento gerencialista neoliberal dos anos 1980).

Da mesma forma, as interseções identificadas entre essas abordagens sugerem que também a parte complementar do que se objetivava foi alcançada. Vários temas elencados, como a contraposição entre gestão social e gestão estratégica, o terceiro setor como um espaço de ocorrência da gestão social, a proeminência de conceitos como participação, diálogo e busca do bem comum nas abordagens, permitem fazer essa afirmação. 
Ao cabo, o que se conclui é que, além da divisão dos estudos da Gestão Social em quatro abordagens, percebe-se uma subdivisão em duas vertentes: uma vinculando-os estritamente à gestão pública, como administração pública societal (PAES DE PAULA, 2005a; 2005b), gestão do desenvolvimento social (FISCHER, 2002) ou gestão do social (DOWBOR, 1999b) e outra que expande seu escopo rumo a uma ação gerencial dialógica que pode (e deve) ser utilizada em diferentes sistemas sociais - públicos, privados ou de organizações não-governamentais (TENÓRIO, 2005; FRANÇA-FILHO, 2008).

Essa divisão indica possibilidades interessantes para discussões futuras. É a Gestão Social um fenômeno restrito à administração pública, como propõe a primeira vertente, ou ações gerenciais dialógicas desenvolvidas em outros domínios, como as organizações privadas ou as não governamentais, também podem ser classificadas como pertencentes a esse mesmo fenômeno, como preconiza a segunda?

Do ponto de vista metodológico, reconhece-se a limitação deste trabalho, que se vale apenas da análise de citações como ferramenta bibliométrica de pesquisa. Sugere-se, para uma melhor delimitação das "escolas teóricas" da Gestão Social, que outros indicadores de atividade científica, indicadores relacionais e indicadores de performance (ou desempenho) sejam utilizados em trabalhos futuros.

\section{Referências}

ALVES SOBRINHO, E.; INOJOSA, R. Gestão social nos municípios: a violência e a cultura de paz. Rev. Adm. Pública, Rio de Janeiro, v. 39, n. 2, p. 279-294, 2005.

BORNMANN, L.; DANIEL, H. What do we know about the h-index? Journal of the American Society for Information Science and Technology, Silver Spring, v. 58, n. 9, p. 1381-1385, July 2007.

CABRAL, E. H. Gestão social no terceiro setor: avaliação de processos e missão institucional. Oficina do CES, Coimbra, Portugal, v. 190, p. 1-43, 2003.

Espaço público e controle para a gestão social no Terceiro Setor. Serviço Social e Sociedade, São Paulo, v. 86, p. 30-55, 2006. 34,2008

A gestão social do terceiro setor e suas dualidades. Administração em Diálogo, São Paulo, v. 11, n. 2, p. 21 -

Uma abordagem normativa para a gestão social no espaço público. In: PEREIRA, J. R. et al. (Orgs.). Gestão social e gestão pública. Lavras: UFLA, 2011. 47-58 p.

CANÇADO, A. C. Fundamentos teóricos da gestão social. Tese (Doutorado em Administração) - Universidade Federal de Lavras, Lavras, MG, 2011.

; TENÓRIO, F. G.; PEREIRA, J. R. Gestão social: reflexões teóricas e conceituais. Cad. EBAPE. BR, Rio de Janeiro, v. 9, n. 3, p. 681-703, 2011.

CARVALHO, M. C. B. Gestão social: alguns apontamentos para debate. In: RICO, E. D. M.; RAICHELIS, R. (Orgs.). Gestão social: uma questão em debate. São Paulo: EDUC/IEE, 1999. 19-29 p.

CAVALCANTI, M.; NOGUEIRA, A. Gestão social, estratégias e parcerias: redescobrindo a essência da administração brasileira de comunidades para o Terceiro Setor. São Paulo: Saraiva, 2006.

CECCIM, R.; FEUERWERKER, L. O quadrilátero da formação para a área da saúde: ensino, gestão, atenção e controle social. Physis, Rio de Janeiro, v. 14, n. 1, p. 41-65, 2004. 
DEMO, P. Participação comunitária e constituição: avanços e ambiguidades. Cadernos de Pesquisa, São Paulo, v. 71, p. 72-81, nov. 1989.

DOWBOR, L. A gestão social em busca de paradigmas. In: RICO, E. D. M.; RAICHELIS, R. (Orgs.). Gestão social: uma questão em debate. São Paulo: EDUC/IEE, 1999a. 31-42 p.

. Tendências da gestão social. Saúde e Sociedade, São Paulo, v. 8, n. 1, p. 3-16, 1999b.

. Gestão social e transformação da sociedade. In: DOWBOR, L.; KILSZTAIN, S. (Orgs.). Economia social no Brasil. São Paulo: Senac, 2001. 17-42 p.

DURIEUX, V.; GEVENOIS, P. A. Bibliometric indicators: quality measurements of scientific publication. Radiology, Oak Brook, IL, v. 255, n. 2, p. 342-351, 2010.

FARAH, M. F. S. Governo local e novas formas de provisão e gestão de serviços públicos no Brasil. Rev. Adm. Pública, Rio de Janeiro, v. 31, n. 3, p. 191-192, 1997.

FISCHER, R. M. Estado, Mercado e Terceiro Setor : uma análise conceitual das parcerias intersetoriais. Revista de Administração, São Paulo, v. 40, n. 1, p. 5-18, 2005.

FISCHER, T. M. D. Administração pública como área de conhecimento e ensino: a trajetória brasileira. Revista de Administração de Empresas, São Paulo, v. 24, n. 4, p. 278-288, 1984.

Poderes locais, desenvolvimento e gestão. In: (Org.). Gestão do desenvolvimento e poderes locais: marcos teóricos e avaliações. Salvador: Casa da Qualidade, 2002. 12-32 p.

. O futuro da gestão. HSM Management, Barueri, SP, v. 64, p. 1-16, 2007.

; MELO, V. P. Gestão Social do desenvolvimento e interorganizações. Colóquio Internacional sobre Poder Local, 12. Anais... Salvador: UFBA, 2003.

FRANÇA FILHO, G. C. Gestão social: um conceito em construção. In: COLÓQUIO INTERNACIONAL SOBRE PODER LOCAL, 9., Salvador, Bahia. Anais..., Salvador: UFBA, 2003.

Definindo gestão social. In: SILVA JUNIOR, J. T. et al. (Orgs.). Gestão Social: Práticas em Debate, Teorias em Construção. Fortaleza: Imprensa Universitária, 2008. 26-37 p.

GONDIM, S. M. G.; FISCHER, T. M. D.; MELO, V. P. Formação em gestão social: um olhar crítico sobre uma experiência de pós-graduação. ENCONTRO DA ASSOCIAÇÃO NACIONAL DE PÓS-GRADUAÇÃO E PESQUISA EM ADMINISTRAÇÃO (EnANPAD), 30., 2006, Salvador. Anais... Salvador: ANPAD, 2006.

HOCAYEN-DA-SILVA, A. J.; ROSSONI, L.; FERREIRA-JÚNIOR, I. Administração pública e gestão social: a produção científica brasileira entre 2000 e 2005. Rev. Adm. Pública, Rio de Janeiro, v. 42, n. 4, p. 655-680, 2008.

INOJOSA, R. M.; JUNQUEIRA, L. A. P. Práticas e saberes: desafios e inovações em gestão social. Organizações \& Sociedade, Salvador, v. 15, n. 45, p. 171-180, 2008.

JUNQUEIRA, L. A. P. Gestão intersetorial das políticas sociais e o terceiro setor. Saúde e Sociedade, São Paulo, v. 13, n. 1, p. 25-36, 2004.

Organizações sem fins lucrativos e redes sociais na gestão de políticas sociais. In: CAVALCANTI, M. (Org.). Gestão social, estratégias e parcerias: redescobrindo a essência da administração brasileira de comunidades para o Terceiro Setor. São Paulo: Saraiva, 2006. 195-216 p. 
KLIKSBERG, B. Hacia una gerencia social eficiente: algunas cuestiones claves. Revista Venezolana de Ciencias Sociales, Caracas, v. 1, n. 1, p. 7-18, 1997.

MUGNAINI, R.; STREHL, L. Recuperação e impacto da produção científica na era Google: uma análise comparativa entre o Google Acadêmico e a Web of Science. Encontros Bibli, Florianópolis, v. 13, n. especial $1^{\circ}$ semestre, p. 92 $105,2008$.

OKUBO, Y. Bibliometric indicators and analysis of research systems: methods and examples. OECD - Science, Technology and Industry Working Papers 1997/1. Paris: OECD Publishing, 1997.

OLIVEIRA, V. A. R.; CANÇADO, A. C.; PEREIRA, J. R. Gestão social e esfera pública: aproximações teóricoconceituais. Cad. Ebape.BR, Rio de Janeiro, v. 8, n. 4, p. 613-626, 2010.

PAES DE PAULA, A. P. Administração pública brasileira entre o gerencialismo e a gestão social. Revista de Administração de Empresas, São Paulo, v. 45, n. 1, p. 36-49, 2005a.

. Por uma nova gestão pública. Rio de Janeiro: FGV, 2005 b. 2005c.

. Tréplica: comparação possível. Revista de Administração de Empresas, São Paulo, v. 45, n. 1, p. 52-53,

PEREIRA, J. R.; RIGATTO, S. H. Gestão social de políticas públicas no contexto das relações entre Estado e sociedade moderna. In: (Orgs.). Gestão social de políticas públicas. Lavras: UFLA, 2011. 17-34 p.

PIMENTEL, M. P. C.; PIMENTEL, T. D. Gestão social e esfera pública: noções e apropriações. In: Congresso Virtual Brasileiro - Administração, 2010. Anais..., [s.1.]: CONVIBRA, 2010.

PINHO, J. A. G. Gestão social: conceituando e discutindo os limites e possibilidades reais na sociedade brasileira. In: RIGO, A. et al. (Orgs.). Gestão social e políticas públicas de desenvolvimento: ações, articulações e agenda. Recife: UNIVASF, 2010. 21-52 p.

RICO, E. M.; RAICHELIS, R. (Orgs.). Gestão social: uma questão em debate. São Paulo: EDUC/IEE, 1999.

RIGO, A. et al (Orgs.). Gestão social e políticas públicas de desenvolvimento: ações, articulações e agenda. Recife: UNIVASF, 2010.

ROSSONI, L.; SILVA, A.; FERREIRA JÚNIOR, I. Aspectos estruturais da cooperação entre pesquisadores no campo de administração pública e gestão social: análise das redes entre instituições no Brasil. Rev. Adm. Pública, Rio de Janeiro, v. 42, n. 6, p. 1041-1067, 2008.

SANTOS, B. Reinventar la democracia: reinventar el estado. Buenos Aires: Consejo Latinoamericano de Ciencias Sociales - CLACSO, 2006. p.112.

SCHOMMER, P. C.; FRANÇA FILHO, G. C. Gestão social e aprendizagem em comunidades de prática: interações conceituais e possíveis decorrências em processos de formação. In: SILVA JÚNIOR, J. T. et al. (Orgs.). Gestão social: práticas em debate, teorias em construção. v. 1. Fortaleza: Imprensa Universitária, 2008. 58-86 p.

SENGUPTA, L. N. Bibliometrics, informetrics, scientometrics and librametrics: an overview. Libri, Munich, v. 42 , n. 2. p. 75-98, 1992.

SILVA, A. A. A gestão da seguridade social brasileira: entre a política pública e o mercado. São Paulo: Cortez, 2004. 
SPINK, P. A democratização do poder local: gestão social na ótica subnacional. In: RICO, E. D. M.; RAICHELIS, R. (Orgs.). Gestão social: uma questão em debate. São Paulo: EDUC/IEE, 1999. 191-208 p.

STREHL, L. O fator de impacto do ISI e a avaliação da produção científica: aspectos conceituais e metodológicos. Ciência da Informação, Brasília, v. 34, n. 1, p. 19-27, 2005.

TAGUE-SUTCLIFFE, J. An introduction to informetrics. Information Processing \& Management, Oxford, v. 28, n. I. p. 1-3, 1992.

TENÓRIO, F. G. (Org.). Gestão social: metodologia, casos e práticas. Rio de Janeiro: FGV, 1998a.

. Gestão social: uma perspectiva conceitual. Rev. Adm. Pública, Rio de Janeiro, v. 32, n. 5, p. 7-23, 1998 b.

. Flexibilização organizacional: mito ou realidade? 2. ed. Rio de Janeiro: FGV, 2002.

Um espectro ronda o terceiro setor: o espectro do mercado. Ensaios de Gestão Social. Ijuí: Unijuí, 2004.

. (Re)Visitando o Conceito de Gestão Social. Desenvolvimento em Questão, Ijuí, v. 5, p. 101-124, 2005.

. A trajetória do Programa de Estudos em Gestão Social (PEGS). Rev. Adm. Pública, Rio de Janeiro, v. 40, n. 6, p. 1145-1162, dez. 2006.

Gestão social: uma réplica. Rev. ADM. MADE, v. 13, n. 2, p. 1-4, 2009.

; DUTRA, J. L. A.; MAGALHÃES, C. M. R. Gestão social e desenvolvimento local: uma perspectiva a partir da cidadania deliberativa. In: ENCONTRO DA ASSOCIAÇÃO NACIONAL DE PÓS-GRADUAÇÃO E PESQUISA EM ADMINISTRAÇÃO (EnANPAD), 28., 2004, Curitiba. Anais... Curitiba: ANPAD, 2004.

; SARAVIA, E. J. Escorços sobre gestão pública e gestão social. In: MARTINS, P. E. M.; PIERANTI, O. P. Estado e gestão pública: visões do Brasil contemporâneo. Rio de Janeiro: FGV, 2006.

VANTI, N. Da bibliometria à webometria: uma exploração conceitual dos mecanismos utilizados para medir o registro da informação e a difusão do conhecimento. Ciência da Informação, Brasília, v. 31, n. 2, p. 152-162, 2002.

VANZ, S. A. S.; CAREGNATO, S. E. Estudos de citação: uma ferramenta para entender a comunicação científica. Em Questão, Porto Alegre, v. 9, n. 2, p. 295-307, 2003.

WANDERLEY, L. E. W. Desafios da sociedade civil brasileira em seu relacionamento dialético com o Estado e o mercado. In: RICO, E. D. M.; RAICHELIS, R. (Orgs.). Gestão social: uma questão em debate. São Paulo: EDUC/IEE, 1999. $105-127 \mathrm{p}$

. Uma proposta inovadora: o público não estatal. Serviço Social e Sociedade, São Paulo, n. 86, p. 78-89, 2006.

; RAICHELIS, R. Gestão pública democrática no contexto do Mercosul. In: SIERRA, G. de. (Org.). Los rostros del Mercosur: el difícil camino de lo comercial a lo societal. Buenos Aires: CLACSO, 2001. 